\title{
Mechanisms of Pulmonary Fibrosis
}

\author{
SPONTANEOUS RELEASE OF THE ALVEOLAR MACROPHAGE-DERIVED \\ GROWTH FACTOR IN THE INTERSTITIAL LUNG DISORDERS
}

\author{
Peter B. Bitterman, Steven Adelberg, and Ronald G. Crystal, Pulmonary \\ Branch, National Heart, Lung, and Blood Institute, \\ Bethesda, Maryland 20205
}

A B S T R A C T Interstitial lung disorders are characterized both by a chronic inflammation of the lower respiratory tract that includes increased numbers of activated alveolar macrophages and by increased numbers of fibroblasts within the alveolar wall. Since alveolar macrophages from normal individuals can be activated to release a growth factor for lung fibroblasts (alveolar macrophage-derived growth factor [AMDGF]), we hypothesized that the activated alveolar macrophages within the lower respiratory tract of patients with fibrotic lung disorders might be spontaneously releasing AMDGF. To evaluate this hypothesis, alveolar macrophages (suspension culture, $4 \mathrm{~h}, 37^{\circ}$ ) from 65 patients with interstitial lung disorders and 30 control subjects were examined for the spontaneous release of fibroblast growth-promoting activity, with human lung fibroblasts as the target. Whereas none of the controls had macrophages spontaneously releasing a growth-promoting activity for fibroblasts, $82 \%$ of the patients with interstitial lung disease had alveolar macrophages that were spontaneously releasing a growthpromoting activity for fibroblasts. In common with AMDGF, the fibroblast growth-promoting activity released by these macrophages eluted from DEAE cellulose at $270 \mathrm{mM} \mathrm{NaCl}$, had a partition coefficient of 0.3 by gel filtration on Sephadex G-50, was distinct from other characterized growth factors, and acted as a progression factor for fibroblast replication in a serumfree complementation test. These data suggest that the expansion of fibroblast numbers within the alveolar structures in interstitial lung disorders may result, in part, from the release of AMDGF by alveolar macrophages stimulated in vivo.

Received for publication 23 March 1983 and in revised form 20 July 1983.

\section{INTRODUCTION}

The interstitial lung disorders are a group of chronic inflammatory disorders of the lower respiratory tract in which the normal alveolar walls are progressively thickened by a fibrotic process characterized by an expansion of fibroblast numbers and a collagenous extracellular matrix secreted by these cells $(1-3)$. Since fibrosis of the alveolar wall is generally an irreversible process, an understanding of the mechanisms modulating the fibrotic state is necessary in order to understand the pathogenesis of these disorders and to develop a therapeutic strategy to prevent the irreversible loss of alveolar-capillary units.

Since the fibrotic process is characterized by expanded numbers of fibroblasts in the alveolar walls (46), mechanisms modulating the development of the fibrosis must involve processes that stimulate fibroblast proliferation. Although the modulation of fibroblast replication is a complex process likely involving several integrated signals, one link between the chronic inflammation and the expansion of fibroblast numbers in these diseases may be provided by the alveolar macrophage, an inflammatory cell that is capable of releasing a growth factor that, under appropriate conditions, can stimulate human lung fibroblasts to replicate (7). This growth factor, termed the alveolar macrophage-derived growth factor (AMDGF), ${ }^{1}$ is an 18,000 -

\footnotetext{
${ }^{1}$ Abbreviations used in this paper: AMDGF, alveolar macrophage-derived growth factor; DLCO, carbon monoxide diffusing capacity (single breath, corrected for hemoglobin, predicted on lung volume); DMEM, Dulbecco'smodified Eagle medium; EGF, epidermal growth factor; FGF, fibroblast growth factor; IPF, idiopathic pulmonary fibrosis; MSA, multiplication-stimulating activity; PDGF, platelet-derived growth factor; TLC, total lung capacity (helium equilibration); VC, vital capacity.
} 
D protein that acts as a "progression factor" to stimulate fibroblast replication in serum-free conditions in the presence of "competence factors" such as platelet-derived growth factor, fibroblast growth factor, or fibronectin $(7,8)$. When cultured in vitro for short periods, alveolar macrophages obtained from normal individuals do not release AMDGF, but when cultured in the presence of stimuli such as immune complexes or particulates, the macrophages release this growth factor (7).

Since the chronic inflammation characterizing the interstitial lung disorders is composed of large numbers of alveolar macrophages that have been presumably activated in vivo $(4-6,9-11)$, it is reasonable to hypothesize that the alveolar macrophages present in the lower respiratory tract of these patients are spontaneously releasing AMDGF, thus providing at least one of the signals for the enhanced fibroblast proliferation found in the alveolar walls of these patients. In this regard, the present study was designed to determine whether alveolar macrophages from patients with a variety of interstitial disorders are spontaneously releasing a growth factor for fibroblasts. The data demonstrate not only that this is the case, but also that this growth factor has biochemical and biological properties similar to AMDGF.

\section{METHODS}

\section{Study population: control subjects (Table I)}

Two control populations were used: normal individuals (referred to as "normals") and patient controls, individuals who underwent bronchoscopy for localized lung disease (referred to as "controls"). In both groups, there was no evidence of diffuse interstitial fibrosis by physical examination, pulmonary function testing, or chest roentgenogram.

The normals ( $n=15$; six males, nine females) had an average age of $22 \pm 2 \mathrm{yr}$ (mean $\pm \mathrm{SEM}$ ) and included three smokers $(4 \pm 1$ pack-yr) and 12 nonsmokers. The controls ( $n$ $=15$; seven males, eight females; age $46 \pm 7 \mathrm{yr}$ ) included 10 smokers and five nonsmokers. Nine patients were not on any current medications, four patients were receiving antibiotics (a cephalosporin and/or an aminoglycoside), and two were receiving bronchodilators (adrenergic inhaler and aminophylline).

\section{Study population: fibrotic lung disease (Table I)}

The interstitial lung disease group, consisting of 65 individuals, was defined as having fibrosis of the alveolar walls by a combination of roentgenographic, physiologic, and morphologic criteria.

Sarcoidosis. A diagnosis of sarcoidosis was made in 26 patients ( 14 males, 12 females; age $36 \pm 4$ yr) by established criteria, including lung biopsy (13). Nine were smokers (12 \pm 3 pack-yr) and 17 were nonsmokers; none was currently receiving therapy. As a group, pulmonary function testing indicated vital capacity (VC) $=74 \pm 3 \%$ predicted, total lung capacity $(\mathrm{TLC})=74 \pm 3 \%$ predicted, and single breath diffusing capacity $(\mathrm{DLCO})=76 \pm 5 \%$ predicted.
Idiopathic pulmonary fibrosis (IPF). IPF was diagnosed in 24 patients ( 16 males, 8 females; age $47 \pm 3$ yr) by established criteria, including open lung biopsy (14). 14 patients were smokers $(21 \pm 6$ pack-yr) and 10 patients were nonsmokers. Eight patients were not on therapy, two patients were receiving cyclophosphamide $(1.5 \mathrm{mg} / \mathrm{kg}$ per $\mathrm{d})$, six were receiving intravenous methylprednisolone $(30 \mathrm{mg} / \mathrm{kg}$ per week), and eight were receiving prednisone $(0.2-1.0 \mathrm{mg} / \mathrm{kg}$ per $\mathrm{d})$. Pulmonary functions included VC $=58 \pm 4 \%$ predicted, TLC $=57 \pm 6 \%$ predicted, and DLCO $=54 \pm 5 \%$ predicted .

Other interstitial lung disorders. This group consisted of 15 patients (nine males, six females; $39 \pm 7 \mathrm{yr}$ ), seven smokers (13 \pm 4 pack-yr), eight nonsmokers; with five different disorders: histiocytosis $X(n=6)$, pulmonary fibrosis associated with collagen vascular disorders $(n=3$; scleroderma, dermatomyositis, and rheumatoid arthritis), berylliosis $(n=2)$, and hypersensitivity pneumonitis $(n=4)$. Histiocytosis X (15) and pulmonary fibrosis associated with the collagen vascular disorders (16) were diagnosed by established criteria, including lung biopsy. Berylliosis (17) was diagnosed by history of occupational exposure, chest roentgenogram demonstrating hilar adenopathy and/or a diffuse interstitial infiltrate, mild to moderate restrictive pulmonary function abnormalities, and a positive beryllium lymphocyte transformation test. Hypersensitivity pneumonitis (18) was diagnosed in one patient by lung biopsy along with precipitating antibodies to thermophilic actinomycetes, and in three pigeon breeders by typical history and associated precipitating antibodies.

\section{Bronchoalveolar lavage}

Patients with interstitial lung disease and individuals from both control groups underwent bronchoalveolar lavage as previously described (19). Briefly, after premedication and local anesthesia, the tip of a fiberoptic bronchoscope was wedged in a subsegmental bronchus of the lingula and five, 20-ml aliquots of sterile saline were infused with each aliquot immediately aspirated. To recover sufficient numbers of alveolar macrophages for biochemical studies, selected patients underwent identical lavages of two additional anatomic locations during the procedure (usually the left lower lobe and the right middle lobe). In the patient controls, the lavage was performed in a lobe on the opposite side of the primary process.

\section{Purification of alveolar macrophages}

To ensure that it was the alveolar macrophages and not contaminating lymphocytes or neutrophils that were releasing the fibroblast growth-promoting activity, unseparated bronchoalveolar lavage cell supernates from the first 11 study patients were compared with $(a)$ supernates of purified macrophages $(>95 \%)$ and purified T lymphocytes $(>90 \%)$ from six patients with sarcoidosis and $(b)$ supernates of purified macrophages $(>95 \%)$ and purified neutrophils from five patients with IPF. Since $>99 \%$ of the fibroblast growth-promoting activity was found in the alveolar macrophage supernates, the bronchoalveolar lavage cells of the remaining study patients were evaluated without further purification of macrophages, unless $<80 \%$ of recovered cells were macrophages. In this situation, macrophages were purified from the total population of cells recovered by bronchoalveolar lavage using Hypaque-Ficoll centrifugation (to remove neutrophils and eosinophils) (20) and/or rosetting with neur- 
aminidase-treated sheep erythrocytes (to remove $\mathrm{T}$ lymphocytes) (21).

\section{Spontaneous release of a growth-promoting activity for fibroblasts by alveolar macrophages}

To produce supernates to be tested for growth-promoting activity, alveolar macrophages were placed in suspension culture $\left(37^{\circ} \mathrm{C}, 4 \mathrm{~h}\right)$ in polypropylene tubes (Falcon, Labware, Div. of Becton, Dickinson \& Co. Cockeysville, MD) at a concentration of $10^{6}$ cells $/ \mathrm{ml}$ in Dulbecco's modified Eagle medium (DMEM, Gibco Laboratories, Grand Island, NY) in a humidified atmosphere of $90 \%$ air $/ 10 \% \mathrm{CO}_{2}$, with no further additions (these macrophages will be referred to as unstimulated macrophages). Cells were removed by centrifugation and resultant macrophage supernates were assayed for growth-promoting activity as detailed below. As a positive control for the ability of each patient's macrophages to release a growth-promoting activity for fibroblasts, a parallel culture of macrophages was incubated with opsonized zymosan (these macrophages will be referred to as stimulated macrophages). The viability of both unstimulated and stimulated macrophages after the 4 -h incubation was always $>90 \%$. Supernates were stored frozen in liquid nitrogen. Both unstimulated and stimulated macrophage supernates were assayed at the same time.

To evaluate macrophage supernates for growth-promoting activity for fibroblasts, noncycling human lung fibroblasts were cultured with the test supernate and the increase in cell number was determined as previously described (7). In brief, noncycling human fetal lung fibroblasts (HFL-l; American Type Culture Collection CCL 153) were prepared for the assay by culturing for $4 \mathrm{~d}\left(37^{\circ} \mathrm{C}, 90 \%\right.$ air, $\left.10 \% \mathrm{CO}_{2}\right)$ in DMEM plus $0.4 \%$ calf serum (Colorado Serum Co., Denver, CO). These noncycling fibroblasts were cultured for 2 additional days with standard dilutions of the macrophage supernate; the media used to dilute the macrophage supernates contained that amount of serum necessary to give a final serum concentration of $0.4 \%$ in all fibroblast cultures. The resultant change in cell number was determined by incubating the fibroblast cultures with trypsin $(0.25 \%$, Gibco Laboratories) and counting the number of cells with an electronic particle counter (Coulter Electronics, Inc., model ZBI; Hialeah, FL). The growth response was expressed as the percent increase in fibroblast number above control (fibroblasts cultured in DMEM plus $0.4 \%$ calf serum without added macrophage supernates). As a positive control to determine the effect of maximum stimulation in each experiment, $10 \%$ calf serum was added to the nonreplicating fibroblasts. This resulted in a 140-160\% increase in cell number after $2 \mathrm{~d}$. The content of growth-promoting activity in a macrophage supernate was quantified as previously described (7): the fibroblast growth response to the set of standard dilutions of a macrophage supernate was determined and the number of growth factor units per $10^{6}$ macrophages per $4 \mathrm{~h}$ (referred to as "units") was taken to be equal to the reciprocal of the dilution resulting in $50 \%$ of the maximum growth response.

\section{Comparison of the fibroblast growth- promoting activity spontaneously released by alveolar macrophages with AMDGF}

To determine whether the fibroblast growth-promoting activity spontaneously released by alveolar macrophages from patients with interstitial lung disorders was similar to AMDGF, two approaches were used: (a) biochemical comparisons and $(b)$ biological comparison of the ability of the fibroblast growth-promoting activity to stimulate fibroblast replication in a serum-free complementation test.

To prepare sufficient amounts of fibroblast growth-promoting activity for biochemical comparison with AMDGF, $10^{8}$ macrophages from each of seven patients with fibrotic lung disease (IPF, $n=3$; sarcoidosis; $n=3$; histiocytosis X, $n=1$ ) were cultured individually in serum-free DMEM for $12 \mathrm{~h}$ with the medium changed every $4 \mathrm{~h}$. The supernate from each patient's macrophages was evaluated separately by both ion-exchange and gel filtration chromatography, and compared with an AMDGF standard that was partially purified as previously described (7). Ion-exchange chromatography was carried out by applying each supernate (dialyzed four changes against $20 \mathrm{vol}$ of starting buffer $[100 \mathrm{mM} \mathrm{NaCl}$, $20 \mathrm{mM}$ Tris $\mathrm{HCl}, \mathrm{pH} 7.0$, at $4^{\circ} \mathrm{C}$ ) to DEAE cellulose (Whatman, Inc., Clifton, NJ). The column was eluted with a linear $\mathrm{NaCl}$ gradient from 100 to $300 \mathrm{mM}$ in the same buffer. Each of the fractions was diluted 100 -fold in DMEM plus $0.4 \%$ calf serum, filtered through a $0.22-\mu \mathrm{m}$ filter (Millipore Corp., Bedford, MA) and assayed for growth-promoting activity. The peak of biological activity on the DEAE cellulose column was chromatographed on Sephadex G-50 in phosphate-buffered saline $\left(\mathrm{pH} 7.2,4^{\circ} \mathrm{C}\right)$. Each fraction was diluted 100 fold in DMEM plus $0.4 \%$ calf serum, filtered through a 0.22 $\mu \mathrm{m}$ filter, and assayed for growth-promoting activity as described above. The column was calibrated with bovine serum albumin, chymotrypsinogen $A$, cytochrome $c$, and bacitracin.

To compare the biological function of the partially purified growth activity spontaneously released by the alveolar macrophages of the seven patients with interstitial lung disease with the AMDGF released by normal human alveolar macrophages stimulated in vitro, a serum-free complementation test was performed. In this test, AMDGF is known to act as a progression factor, i.e., it synergistically stimulates fibroblast replication in the presence of characterized competence factors such as fibroblast growth factor (FGF) or platelet-derived growth factor (PDGF), but not in the presence of characterized progression factors such as insulin or multiplication-stimulating activity (MSA). The complementation test was performed as previously described (7). Briefly, nonreplicating fibroblasts in serum-free DMEM supplemented with bovine serum albumin (Sigma Chemical Co., St. Louis, MO, RIA Grade) were cultured with a known competence factor (FGF or PDGF); or a known progression factor (insulin or MSA at the concentrations indicated in the text [22]). To those cultures, either AMDGF from normals or the partially purified growth activity from each of the seven patients was added and the cultures continued for 3 d. After this interval, cell number was determined. As a positive control, FGF $(5 \mathrm{ng} / \mathrm{ml})$ or PDGF $(0.1 \mathrm{unit} / \mathrm{ml})$ was added along with MSA $(20 \mathrm{ng} / \mathrm{ml})$ or insulin $(10 \mu \mathrm{g} / \mathrm{ml})$; in all cases this resulted in an increase in cell number after 3 d ranging from 65 to $85 \%$ above control.

\section{Comparison of AMDGF recovered from patients with other characterized growth factors}

AMDGF from patients was compared with other growth factors as previously described (7). Briefly, patient AMDGF was compared with PDGF and FGF using ion-exchange chromatography. Gel filtration was used to compare patient 
AMDGF with epidermal growth factor (EGF). AMDGF from patients was compared with the insulinlike growth factors in a combination of radioimmunoassay $(23,24)$ and radioreceptor assays $(25,26)$. Patient AMDGF was compared with interleukin-1 by biological assays (each factor was tested in both the standard thymocyte assay for interleukin1 (27) and the standard fibroblast replication assay described above), and was compared with interleukin-2 in a murine CT6 cell bioassay (28). EGF, FGF, and MSA were obtained from Collaborative Research Inc., Waltham, MA, and insulin was from Sigma Chemical Co. PDGF was partially purified according to the method of Vogel et al. (29). Interleukin-1 was prepared from alveolar macrophages and blood monocytes by ion-exchange and gel filtration chromatography as previously described (30), and the interleukin-2 standard was a crude supernate of lectin-stimulated rat spleen cells (28).

\section{Effect of cigarette smoking and the} intensity of alveolitis on the quantity of growth factor released by macrophages from patients with sarcoidosis

Patients with sarcoidosis were categorized as nonsmokers if they never smoked or had not smoked any cigarettes for $>6$ mo before study. Patients were considered smokers if they were currently smoking or had stopped smoking $<6$ mo before study. The intensity of the alveolitis was graded as high intensity or low intensity as previously described (31). Briefly, the high intensity alveolitis state was defined when the percentage of bronchoalveolar cells that were lymphocytes was $>28 \%$ and the gallium-67 scan was positive, and the low intensity alveolitis state when the lymphocyte were $<28 \%$ or gallium-67 scan was negative or both. For each group, the quantity of growth factor in macrophage supernates was determined.

\section{Effect of cigarette smoking, the intensity of} the alveolitis, and therapy on the quantity of growth factor released by alveolar macrophages from patients with IPF

The smoking status of patients with IPF was categorized as described for sarcoidosis. The intensity of the alveolitis was assessed by two separate criteria: $(a)$ the percentage of bronchoalveolar lavage cells that were neutrophils (with a higher percentage indicating a more intense alveolitis) $(32$, $33)$; and (b) gallium-67 scanning with a positive scan indicating a more active inflammation $(33,34)$. Therapy status included four categories: $(a)$ no therapy, $(b)$ cyclophosphamide, $(c)$ intravenous methylprednisolone, and $(d)$ prednisone, as detailed in the description of the study population. For each group, the quantity of growth factor in macrophage supernates was determined.

\section{Statistical evaluations}

All comparisons between mean values were performed using the two-tailed Student's $t$ test.

\section{RESULTS}

Bronchoalveolar lavage. The 95 individuals in the study underwent bronchoalveolar lavage without difficulty. Collectively, the two control groups (normals and patient controls) had normal bronchoalveolar lavage cell differentials (Table I). In the patients with sarcoidosis, an increased proportion of their bronchoalveolar lavage cells were lymphocytes, and in the patients with IPF, there was an increased proportion of neutrophils among the cells recovered. The group of patients comprising the miscellaneous interstitial disorders showed the expected heterogeneity of bronchoalveolar lavage cells.

Growth of lung fibroblasts in response to macrophage supernates. When noncycling fibroblasts were cultured with the supernates of unstimulated macrophages from patients with interstitial lung disease, there was a marked increase in replication rate (Fig. 1). Lung fibroblasts cultured in DMEM plus $0.4 \%$ calf serum gradually decreased their replication rate over a 4-d period (Fig. $1 \mathrm{~A}$ ). At that point, the fibroblasts were noncycling, i.e., they manifested a very slow rate of replication. Supernates of unstimulated macro-

TABLE I

Clinical, Physiologic, and Bronchoalveolar Lavage Characteristics of the Study Population

\begin{tabular}{|c|c|c|c|c|c|c|c|c|c|c|c|c|}
\hline \multirow[b]{3}{*}{ Group } & \multirow[b]{3}{*}{$\mathrm{n}$} & \multicolumn{3}{|c|}{ Clinical data } & \multirow{2}{*}{\multicolumn{4}{|c|}{ Pulmonary function tests ${ }^{\circ}$}} & \multirow{2}{*}{\multicolumn{4}{|c|}{ Bronchoalveolar lavaget }} \\
\hline & & & & & & & & & & & & \\
\hline & & Age & $(\mathbf{M} / \mathbf{F})$ & Nonsmokers & $\mathrm{vc}$ & TLC & DLCO & $\mathrm{FEV}_{1} \%$ & Macrophages & Lymphocytes & Neutrophils & Eosinophils \\
\hline & & yr & & & & & & & & & & \\
\hline Normals & 15 & $22 \pm 2$ & $6 / 9$ & $3 / 12$ & $91 \pm 5$ & $104 \pm 6$ & $94 \pm 4$ & $98 \pm 2$ & $94 \pm 3$ & $6 \pm 1$ & 0 & 0 \\
\hline Controls & 15 & $46 \pm 7$ & $7 / 8$ & $10 / 5$ & $81 \pm 8$ & $83 \pm 9$ & $78 \pm 7$ & $95 \pm 3$ & $90 \pm 5$ & $7 \pm 2$ & $2 \pm 1$ & $1 \pm 1$ \\
\hline Sarcoidosis & 26 & $36 \pm 4$ & $14 / 12$ & $9 / 17$ & $74 \pm 3$ & $74 \pm 3$ & $76 \pm 5$ & $103 \pm 4$ & $72 \pm 7$ & $25 \pm 4$ & $1 \pm 1$ & $2 \pm 1$ \\
\hline IPF & 24 & $47 \pm 3$ & $16 / 8$ & $14 / 10$ & $58 \pm 4$ & $57 \pm 6$ & $54 \pm 5$ & $109 \pm 5$ & $75 \pm 6$ & $8 \pm 3$ & $14 \pm 2$ & $3 \pm$ \\
\hline Others & 15 & $39 \pm 7$ & $9 / 6$ & $7 / 8$ & $72 \pm 11$ & $68 \pm 9$ & $70 \pm 12$ & $96 \pm 4$ & $80 \pm 11$ & $10 \pm 9$ & $6 \pm 6$ & $4 \pm 3$ \\
\hline
\end{tabular}

- $\mathrm{FEV}_{1} \%=[($ forced expiratory vol in $1 \mathrm{~s}) /($ forced $\mathrm{VC})] \times 100$; all values are expressed as percent predicted (see reference $12 \mathrm{for}$ details). $\ddagger$ Expressed as percentage of total cells recovered. 

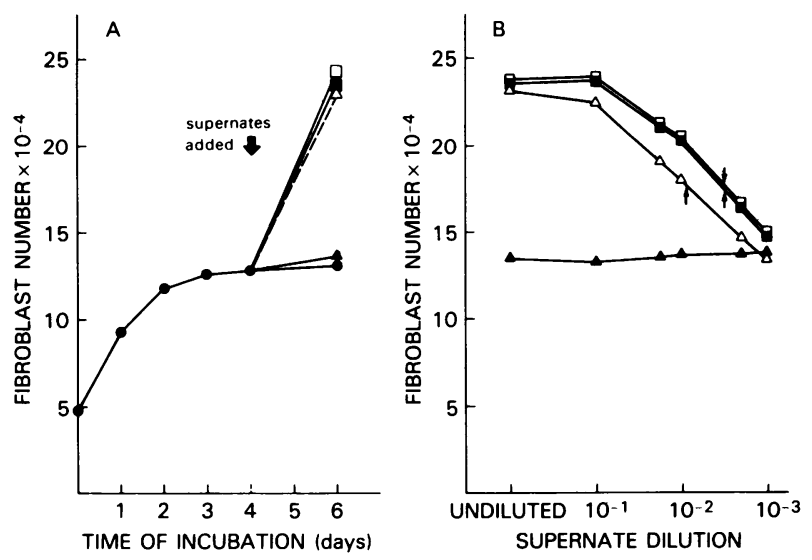

Figure 1 Example of the spontaneous release of AMDGF by alveolar macrophages from a patient with fibrotic lung disease. Shown are data from a patient with IPF. (A) Growth of human lung fibroblasts cultured with macrophage supernates. Fibroblasts were cultured at $5 \times 10^{4}$ cells $/ 35-\mathrm{mm}$ dish in assay medium (DMEM plus $0.4 \%$ calf serum). On day 4 (arrow), fibroblasts were cultured with fresh assay medium (•) or undiluted supernates from alveolar macrophages from a normal individual $(\Delta)$, alveolar macrophages stimulated with zymosan from the same individual $(\Delta)$, alveolar macrophages from a patient with IPF ( $\square)$, and alveolar macrophages stimulated with zymosan from the same patient ( $\square$ ). Shown is the increase in fibroblast number after $2 \mathrm{~d}$ incubation with these macrophage supernates. $(B)$ Quantitation of the amount of AMDGF'released by macrophages shown in panel $A$. Fibroblasts cultured as described above were exposed to the same macrophage supernates on day 4 at the dilutions indicated. Shown is fibroblast number determined on day 6 as a function of macrophage supernate dilution. The number of growth factor units present in a supernate is defined as the reciprocal of the dilution resulting in $50 \%$ of the maximum growth response (indicated by arrows); e.g., for the IPF patient, the alveolar macrophages released 220 growth factor units $/ 4$ h from $10^{6}$ cells.

phages from normal individuals added to these noncycling fibroblasts had little effect on fibroblast replication. In marked contrast, in the example shown (Fig. $1 \mathrm{~A})$, culturing noncycling fibroblasts with supernates from unstimulated macrophages from a patient with IPF resulted in an $83 \%$ increase in cell number within $2 \mathrm{~d}$. Although stimulation of the macrophages from the normal individual with opsonized zymosan resulted in a supernate causing a substantial increase $(79 \%)$ in fibroblast number after $2 \mathrm{~d}$, stimulation of the macrophages from the patient with IPF resulted in no additional release of fibroblast growth-promoting activity. This suggested that these macrophages were stimulated in vivo and could not be stimulated further to release the growth-promoting activity.

The quantity of growth-promoting activity in the macrophage supernates was best estimated by determining the growth response to a set of dilutions (un- diluted, 1:10; 1:50; 1:100; 1:500; 1:1,000) (Fig. 1 B). The reciprocal of the dilution resulting in $50 \%$ of the maximum growth response was taken to be equal to the number of growth factor units present. This was a highly reproducible value; for example, eight determinations of each of 10 supernates stored frozen in liquid nitrogen vapor over a 6-mo period gave a mean coefficient of variation of $11 \%$. In the example shown, the maximum increase in cell number for the stimulated macrophage supernate from the normal individual was 100,000 cells above the number present with medium alone. $50 \%$ of this increase $(50,000$ cells above medium alone) occurred at a dilution of 1:100; therefore, there were 100 growth factor units present. The supernate of both the stimulated and unstimulated macrophages from the patient with IPF caused $50 \%$ of its maximum growth response at a dilution of $1: 220$, indicating that $\mathbf{2 2 0}$ growth factor units were present in both supernates.

Spontaneous release of growth-promoting activity by alveolar macrophages from patients with interstitial lung disease. None of the macrophages from normal individuals or patient controls spontaneously released significant amounts of growth-promoting activity (Fig. 2). In contrast, $82 \%$ of patients with interstitial lung disease had alveolar macrophages spontaneously releasing growth-promoting activity for fibroblasts. Analysis of fibroblast growth in response to supernates of macrophages from patients with interstitial lung disease revealed a bimodal pattern; supernates either contained at least 50 growth factor units or none at all. This permitted a clear distinction to be made between macrophages releasing growth-promoting activity and those not releasing growth-promoting activity. In this context, alveolar macrophages were found to be spontaneously releasing a growth promoting activity for fibroblasts in 18 of 26 patients with sarcoidosis, all 24 patients with IPF, and in 11 of 15 patients with other interstitial lung disorders. In the $82 \%$ of patients with macrophages that were releasing fibroblast growth-promoting activity, the quantity of growth promoting activity varied somewhat among the different disorders ranging from 50 to 420 units in sarcoidosis (216 \pm 27 units), 150 to 580 units in IPF ( $308 \pm 24$ units), and from 80 to 585 units in the other interstitial disorders (245 \pm 35 units). Despite this quantitative variation, however, growth-promoting activity was spontaneously released by macrophages from most patients with interstitial lung disease, and from none of the controls.

Since alveolar macrophages from $18 \%$ of the patients with interstitial disease and from all of the individuals in both control groups were not spontaneously releasing the growth-promoting activity for fibroblasts, it was important to determine whether the recovered mac- 

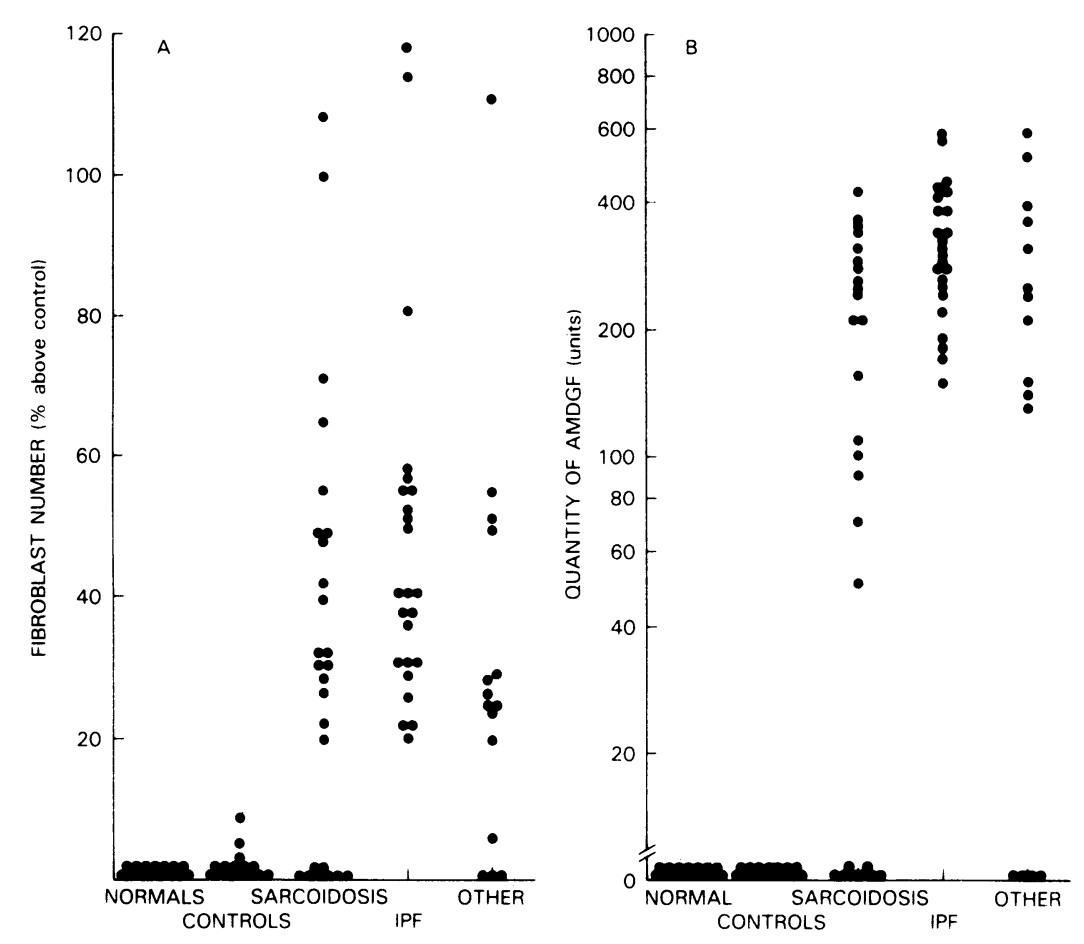

FIgURE 2 Spontaneous release of AMDGF by alveolar macrophages from patients with interstitial lung disease. $(A)$ Growth of fibroblasts in response to macrophage supernates. Noncycling fibroblasts were cultured with undiluted supernates from alveolar macrophages $\left(2 \mathrm{~d}, 37^{\circ} \mathrm{C}\right)$, and the resultant increase in fibroblast number was determined. Shown is the percent increase in fibroblast number above control (medium alone) caused by macrophage supernates from the different patient groups. (B) Quantity of AMDGF released spontaneously by macrophages from the different patient groups shown in panel $A$. The quantity of growth factor was determined as outlined in the legend to Fig. $1 B$.

rophages were capable of releasing this activity. In this context, when macrophages were spontaneously releasing growth-promoting activity, no additional activity was released with zymosan stimulation, suggesting these cells were maximally stimulated in vivo. In contrast, when macrophages were not spontaneously releasing growth-promoting activity, zymosan stimulation resulted in a substantial release of this activity ranging from 45 to 190 units in the two control groups and from 80 to 580 units in patients. This inducibility of growth-promoting activity release in macrophages that were not spontaneously releasing this activity established that the cells obtained were capable of this function if appropriately stimulated. In addition, this observation suggested that these macrophages had not been stimulated in vivo.

Cell source of the growth-promoting activity for fibroblasts. When bronchoalveolar lavage cells of patients with interstitial lung disease were separated into highly enriched cell fractions, essentially all of the growth-promoting activity was found in the alveolar macrophage supernates. Cultures of bronchoalveolar lavage cells from patients with active sarcoidosis (i.e., high intensity alveolitis) resulted in supernates containing between 200 and 420 growth factor units. In each case, $\geq 99 \%$ of the activity was found to be released by the alveolar macrophages, while $<1 \%$ of the activity was released by the lymphocyte fraction (data not shown). Because the amount of growth-promoting activity from the lymphocyte fraction was so low, insufficient material was available to permit characterization, and it was not possible to determine whether a separate growth factor derived from lymphocytes was present or whether the few contaminating macrophages were responsible. For the patients with active IPF ( $>10 \%$ neutrophils) and the other interstitial disorders, similar results were obtained, indicating that alveolar macrophages were the predominant source of the observed fibroblast growth-promoting activity.

Comparison of the growth-promoting activity spontaneously released by alveolar macrophages from patients with interstitial lung disease with AMDGF and other characterized growth factors. The growthpromoting activity in macrophage supernates from 
patients with interstitial lung disease coeluted with AMDGF on both anion exchange and gel filtration chromatography (Fig. 3). Greater than $99 \%$ of the recovered fibroblast growth-promoting activity eluted at $\sim 270 \mathrm{mM} \mathrm{NaCl}$ on DEAE-cellulose chromatography, similar to AMDGF released from stimulated normal alveolar macrophages. In addition, chromatography of the peak of the DEAE cellulose column on Sephadex G-50 indicated that all of the biological activity coeluted with AMDGF with a partition coefficient of 0.3 . On the basis of biochemical criteria, therefore, it appeared that the growth-promoting activity from macrophages of patients with interstitial disease was similar to AMDGF released from normal stimulated alveolar macrophages.

A serum-free complementation test indicated that similar to AMDGF, the partially purified growth factor from patients was a progression factor (Fig. 4). In this test, the growth-promoting activity released from the macrophages (referred to as AMDGF in all cases in Fig. 4 and the subsequent text) alone had no effect on fibroblast growth. Likewise, the progression factors
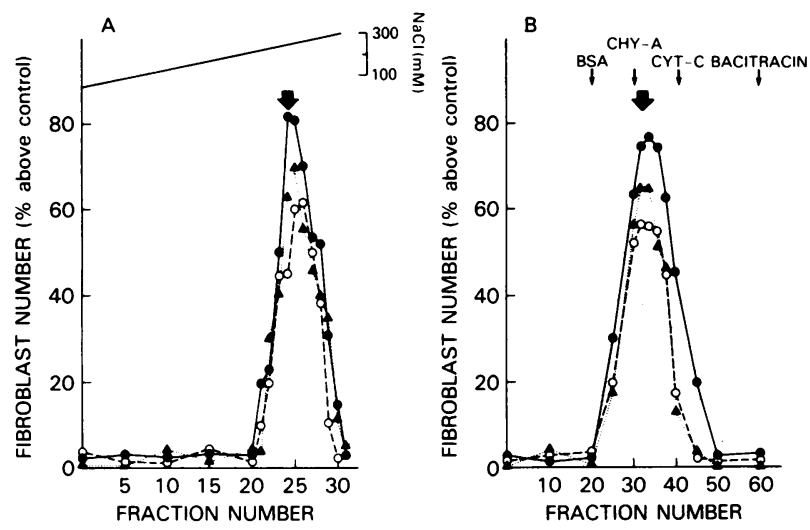

Figure 3 Biochemical properties of the growth factor released spontaneously by alveolar macrophages from patients with interstitial lung disease. (A) DEAE-cellulose chromatography. Macrophages purified from three patients (sarcoidosis [O], IPF [O], and histiocytosis X [A]) were cultured individually $\left(24 \mathrm{~h}, 37^{\circ} \mathrm{C}\right)$ and the resultant supernates were chromatographed in separate column runs on DEAE-cellulose. Each column was eluted with a $\mathrm{NaCl}$ gradient from 100 to $300 \mathrm{mM}$ as indicated. Shown is the fibroblast growth response to a 1:100 dilution of the different column fractions. The position of elution of AMDGF purified from normal alveolar macrophage supernates is indicated by the arrow. (B) Sephadex G-50 chromatography of the peak of growth factor activity from the DEAE-cellulose column. Shown is the fibroblast growth response to a 1:100 dilution of the different column fractions for each patient. The position of elution of AMDGF purified from normal alveolar macrophages is indicated by the arrow. Molecular weight markers included bovine serum albumin (BSA, 67,000 D), chymotrypsinogen A (CHY-A, 25,000 D), cytochrome $c$ (CYT-C, $12,000 \mathrm{D})$, and bacitracin $(1,450 \mathrm{D})$.

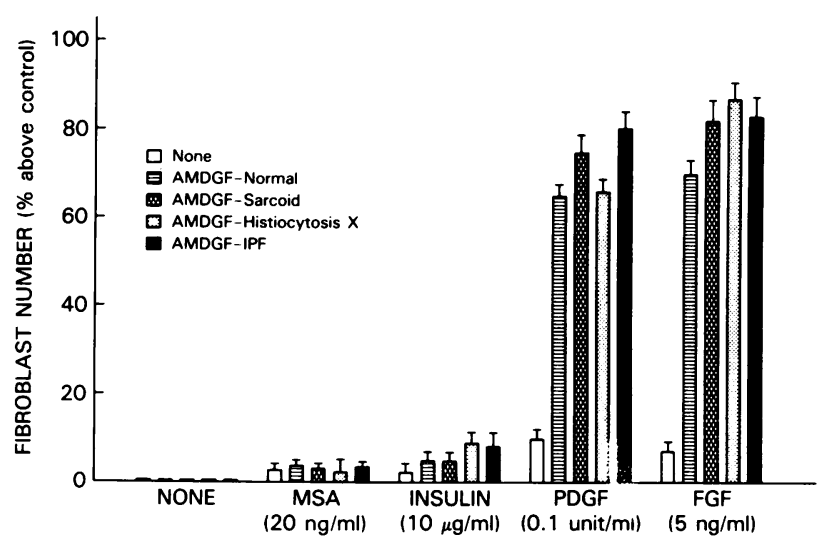

Figure 4 Serum-free complementation test to determine whether the growth factor released spontaneously by alveolar macrophages from patients is a progression factor. AMDGF partially purified from three patients with interstitial lung disease (sarcoidosis, IPF, and histiocytosis $\mathrm{X}$ ) were compared with AMDGF from normal individuals for its ability to act as a progression factor by promoting fibroblast replication in combination with known competence factors. Nonreplicating fibroblasts were cultured in serum-free conditions with the growth factor from the four sources (referred to as AMDGF in all cases) along with either a competence factor (FGF or PDGF) or a progression factor (insulin or MSA) in the amounts indicated. Fibroblast number was determined after $3 \mathrm{~d}$. Shown is the percent increase in cell number above control for the different combinations of growth factors.

(MSA, $20 \mathrm{ng} / \mathrm{ml}$; insulin, $10 \mu \mathrm{g} / \mathrm{ml}$ ) alone had no effect nor did the competence factors (PDGF, $0.1 \mathrm{unit} / \mathrm{ml}$; $\mathrm{FGF}, 5 \mathrm{ng} / \mathrm{ml}$ ) alone. Furthermore, when nonreplicating fibroblasts were cultured with a progression factor (MSA, $20 \mathrm{ng} / \mathrm{ml}$, or insulin, $10 \mu \mathrm{g} / \mathrm{ml}$ ) plus AMDGF (from normals or patients, dilution 1:100) there was no effect on fibroblast replication. In contrast, when nonreplicating fibroblasts were cultured with an increasing dose of competence factors (PDGF, 0.01-0.1 units $/ \mathrm{ml}$, or FGF, $1-5 \mathrm{ng} / \mathrm{ml}$ ) along with a fixed dose of AMDGF (dilution 1:100), there was a dose-related increase in cell number within $3 \mathrm{~d}$, ranging from $21 \%$ above control for the lowest doses of PDGF and FGF up to $87 \%$ above control for the highest doses. Moreover, the addition of increasing amounts of AMDGF (1:10,000 to 1:100) to a fixed dose of PDGF (0.1 units/ml) or FGF (5 ng/ $\mathrm{ml}$ ) resulted in a dose-dependent increase in cell number ranging from $34 \%$ for the lowest dose of AMDGF up to $87 \%$ for the highest.

By evaluation with the appropriate assay (Methods), it was apparent that, like AMDGF, the growth-promoting activity released from macrophages of the patients was distinct from interleukin-1, interleukin-2, PDGF, FGF, EGF, and the insulinlike growth factors (data not shown). AMDGF from patients was distin- 
guished from interleukin-1 by the inability of AMDGF to stimulate the replication of mouse thymocytes (with both alveolar macrophage and peripheral blood monocyte interleukin-1 as positive controls) and by the inability of either alveolar macrophage or blood monocyte interleukin-1 to stimulate the replication of noncycling fibroblasts (with both patient and normal AMDGF as positive controls). Furthermore, AMDGF from patients was unable to stimulate the replication of murine CT6 cells, thus distinguishing it from interleukin-2. Patient AMDGF bound avidly to DEAE cellulose $(100 \mathrm{mM}$ $\mathrm{NaCl}, 20 \mathrm{mM}$ Tris $\mathrm{HCl}, \mathrm{pH} 7.0$ ) whereas PDGF and FGF did not. In addition, AMDGF from patients had an elution pattern by gel filtration chromatography on Sephadex G-50 that was clearly distinct from EGF.
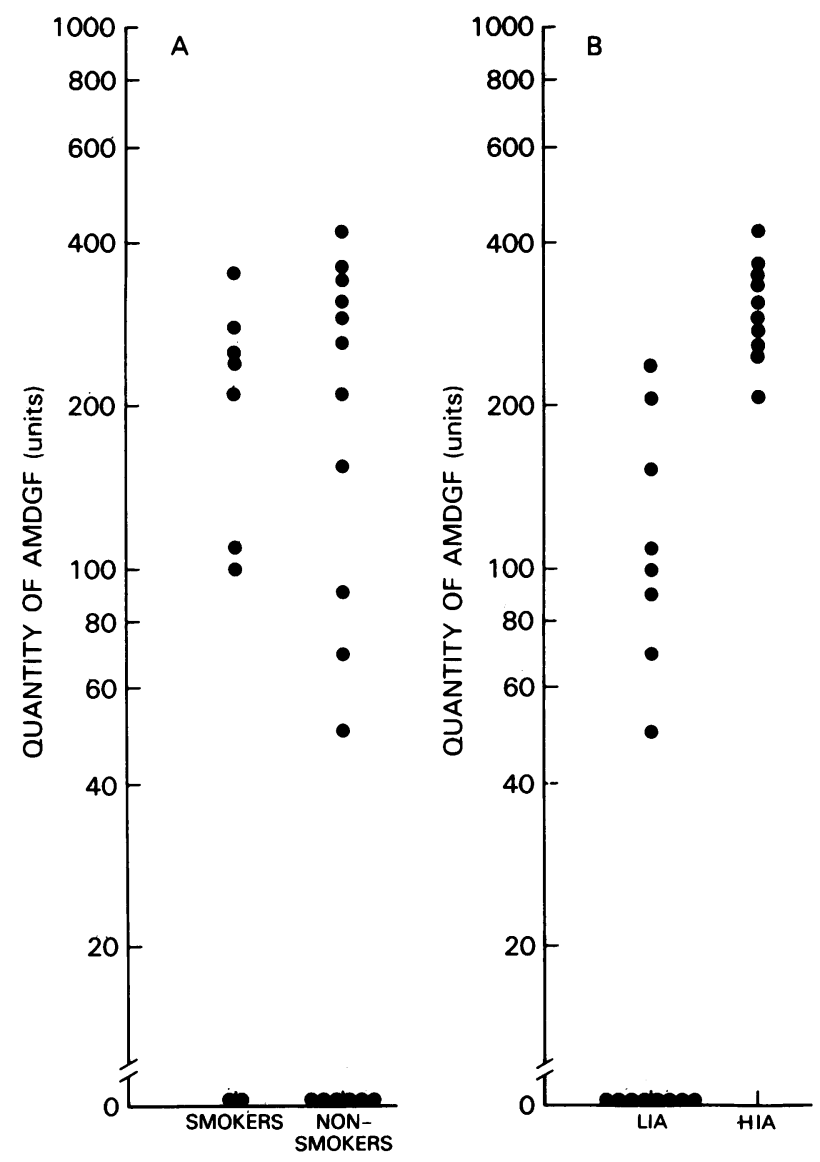

Figure 5 Effect of smoking and the intensity of alveolar inflammation on the quantity of AMDGF released by macrophages from patients with sarcoidosis. Shown is the quantity of AMDGF in macrophage supernates of patients in each group. (A) Effect of smoking on the amount of AMDGF released. $(B)$ Patients were grouped into those with low intensity alveolitis (LIA; T lymphocytes $\leq 28 \%$ and/or negative ${ }^{67} \mathrm{Ga}$ scan) and high-intensity alveolitis (HIA; T lymphocytes $>28 \%$ and positive ${ }^{67} \mathrm{Ga}$ scan) as indicated in Methods.
Furthermore, AMDGF was unable to interact with the receptors or antibodies for the insulinlike growth factors.

Effect of smoking and the intensity of the alveolitis on the quantity of AMDGF released by patients with sarcoidosis. Smoking had no significant effect on AMDGF release in sarcoidosis (smokers $180 \pm 44$ units; nonsmokers $120 \pm 34$ units; $P>0.1$ ) (Fig. 5 A). In contrast, the intensity of the alveolitis in sarcoidosis was an important determinant of the amount of AMDGF released (Fig. 5 B). In this regard, patients with high intensity alveolitis (based on a combination of the proportion of lymphocytes in bronchoalveolar lavage and gallium-67 scanning) had macrophages releasing more AMDGF than those with low intensity alveolitis $(280 \pm 34$ vs. $114 \pm 58, P<0.05)$. In addition, alveolar macrophages from all 10 patients with high intensity alveolitis were spontaneously releasing AMDGF while only 8 of 16 patients with low intensity alveolitis had macrophages releasing AMDGF, further strengthening the relationship between active sarcoidosis and the release of AMDGF.

Effect of smoking, intensity of the alveolitis, and therapy on the quantity of AMDGF released by patients with IPF. None of the clinical parameters examined in patients with IPF had a significant effect on the quantity of AMDGF released (Fig. 6). As noted above, all patients with IPF had macrophages that were spontaneously releasing AMDGF. Smokers released $301 \pm 40$ units and nonsmokers released $291 \pm 38$ units $(P>0.3)$ (Fig. $6 A)$. In contrast to sarcoidosis, the quantity of AMDGF was not significantly affected by the intensity of the alveolar inflammation as assessed by the percentage of bronchoalveolar lavage cells that were neutrophils $(P>0.1$, all comparisons) and the gallium-67 scan $(P>0.1$, comparison of gallium-67 scan positive vs. gallium-67 scan negative) (Fig. 6 B). Moreover, the amount of AMDGF released by macrophages from patients treated with cyclosphosphamide or parenteral or oral corticosteroids was not different from the amount released by macrophages from untreated patients $(P>0.3$, all comparisons) (Fig. $6 C)$.

\section{DISCUSSION}

An increase in the number of fibroblasts within the alveolar structures is a central feature of the interstitial lung disorders (4-6). In the normal lung, the alveolar fibroblast population size is maintained within narrow limits by a very low rate of replication (35), indicating a balance of growth modulating factors within the alveolar microenvironment. An increase in fibroblast number, resulting at least in part from fibroblast replication, suggests that the balance of signals modulat- 

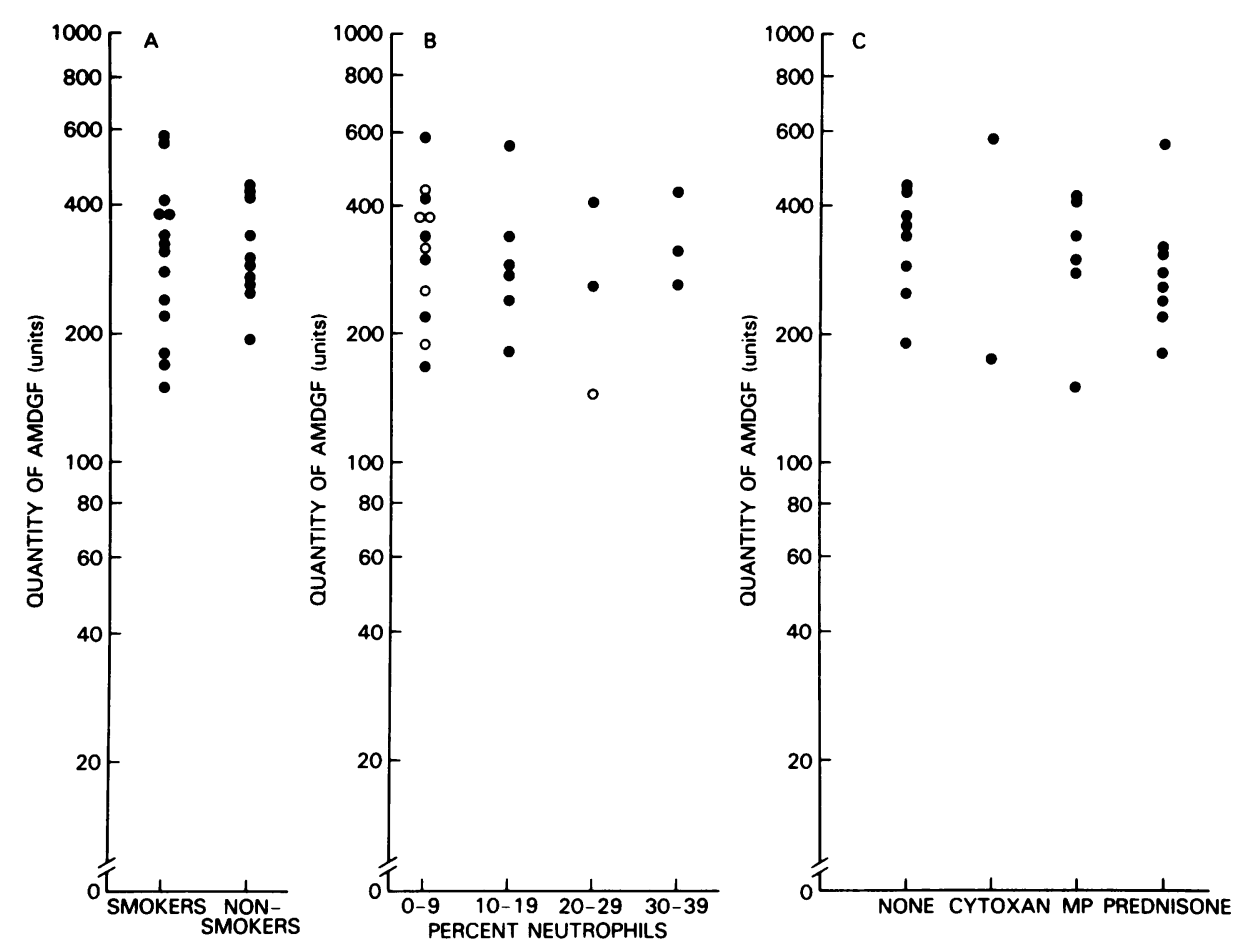

FIGURE 6 Effect of smoking, the intensity of alveolar inflammation, and therapy on the quantity of AMDGF released by macrophages from patients with IPF. Shown is the quantity of AMDGF in macrophage supernates of IPF patients in each group. (A) Effect of smoking on the quantity of AMDGF released. $(B)$ Effect of the intensity of alveolar inflammation on the quantity of AMDGF released. Patients were grouped according to the percentage of recovered bronchoalveolar lavage cells that were neutrophils with a higher percentage indicating more intense inflammation. Within each group, a second measure of the inflammation $\left({ }^{67} \mathrm{Ga}\right.$ scans) are indicated as positive (O) or negative (O). (C) Effect of therapy on the quantity of AMDGF released. Patients were grouped into those on no therapy (None), and those receiving cyclophosphamide (Cytoxan), intravenous methylprednisolone (MP), and prednisone.

ing fibroblast replication favors an increased rate of replication, i.e., that the lower respiratory tract of patients with interstitial lung disease is exposed to lower concentrations of growth-inhibitory factors and/or higher concentrations of growth-promoting factors. In this context, the present study demonstrates that alveolar macrophages from most patients with interstitial lung disease are spontaneously releasing a growth factor for human lung fibroblasts. Analysis of this growth factor reveals that it is biochemically and biologically similar to AMDGF, a characterized growth factor released by normal alveolar macrophages stimulated in vitro. The factors coelute on ion-exchange and on gel filtration chromatography, both act in a serum-free complementation test as progression factors, and both are distinct from other characterized growth factors.

In vivo mechanisms stimulating alveolar macrophages to release AMDGF in the interstitial lung disorders. Although the mechanisms stimulating the alveolar macrophages to release AMDGF in vivo are not known for all of the interstitial disorders, there is circumstantial evidence identifying these stimuli in sarcoidosis and IPF.

In active sarcoidosis, the lower respiratory tract contains large numbers of activated $\mathrm{T}$ lymphocytes (3638). Although the $T$ cell mediators responsible for macrophage release of AMDGF are not known, supernates from activated blood $T$ cells are known to stimulate normal lung alveolar macrophages to release AMDGF (39). Consistent with the concept that the activated $T$ cells can play a role in stimulating the macrophages to release AMDGF, macrophages from patients with sarcoidosis, with high intensity alveolitis (a state characterized by large numbers of activated $T$ cells in the lower respiratory tract) are releasing more AMDGF than macrophages from patients with sarcoidosis and low intensity alveolitis.

In IPF, the stimulus for AMDGF release is likely immune complexes (9). In this regard, immune com- 
plexes (both IgG-immune complexes, IgM-C3b-immune complexes) stimulate normal alveolar macrophages to release AMDGF (7). Furthermore, immune complexes are known to be present in the lower respiratory tract of patients with IPF, and are present on the surface of alveolar macrophages recovered from these individuals (9).

In contrast to sarcoidosis, the intensity of alveolar inflammation did not influence the quantity of AMDGF released by macrophages from patients with IPF. This observation suggests that at least some of the mechanisms influencing the intensity of the alveolar inflammation (e.g., the quantity of neutrophils in the lung in IPF) are acting independently of the mechanisms influencing AMDGF release. This is of interest because neutrophil attraction to the lower respiratory tract in IPF is also thought to result from immune complex stimulation of alveolar macrophages to release a mediator, in this case, the neutrophil chemotactic factor $(9,40,41)$. One possible explanation for this observation is that the two mediators, AMDGF and neutrophil chemotactic factor, are released by different populations of alveolar macrophages.

Interestingly, neither treatment with cyclosphosphamide nor oral or parenteral corticosteroids influenced the quantity of AMDGF released by IPF alveolar macrophages. This is an important observation, as it suggests that the commonly used therapies for IPF have little influence on the release of at least one of the mediators likely responsible for the development of fibrosis in this disease.

IPF is a progressive fibrotic disorder (14), and consistent with a putative role for AMDGF in this clinical course, all patients have macrophages releasing this mediator. Likewise in sarcoidosis, a disease characterized by progressive fibrosis in only $10-20 \%$ of cases $(42,43)$, several patients do not have macrophages spontaneously releasing AMDGF. When the data from patients with sarcoidosis are analyzed according to the degree of alveolitis, all patients with high intensity alveolitis have macrophages releasing AMDGF, whereas only $50 \%$ of patients with low intensity alveolitis have macrophages releasing AMDGF. Significantly, high intensity alveolitis is highly correlated with clinical deterioration, whereas low intensity alveolitis is correlated with clinical stability (31).

Possible mechanisms of fibrosis in interstitial lung disease. A feature common to all of the interstitial lung disorders is that the alveolar inflammation characterizing these diseases, which is invariably composed of increased numbers of alveolar macrophages, precedes and coexists with an expansion of the mass of the pulmonary interstitium by increased numbers of fibroblasts and connective tissue products secreted by these fibroblasts $(1-3,14,42)$. The concept that mononuclear phagocytes could modulate fibroblast function to produce lung disease was first suggested by Heppleston and Styles (44) in their studies of the mechanism of silica-induced fibrosis. This work led to the hypothesis that pulmonary fibrosis resulted largely from a mononuclear phagocyte-directed increase in the amount of collagen produced per fibroblast. Many workers have attempted to reproduce these observations, using silica as well as a variety of macrophage-activating agents. The results have been variable including decreases (45), no change (46), and increases (44) in fibroblast collagen production. Reconciling these findings is difficult because of methodological differences (47). Consequently, it is reasonable to conclude that the role of mononuclear phagocyte factors that direct an increase in collagen production per fibroblast remains uncertain. In this regard, an alternative hypothesis to explain the mechanism of pulmonary fibrosis is that the fibrotic process results from a mononuclear phagocyte-directed expansion of the number of fibroblasts within the alveolar structures without necessarily changing collagen production by each cell. Three separate lines of evidence suggest that the latter hypothesis is valid.

First, morphological studies in both animals and humans with fibrotic lung disorders indicate an increase in the number of fibroblasts within the alveolar structures. Morphometric analysis of rats exposed to hyperoxia has demonstrated a substantial increase in fibroblast number (48). In addition, morphometric studies of rats dusted with asbestos (49) or exposed to lung irradiation (50) have also shown expansion of the fibroblast population. Moreover, autoradiographic analyses of lungs from mice exposed to butylated hydroxytoluene and hyperoxia in vivo demonstrate fibroblasts actively synthesizing DNA (51). Furthermore, ultrastructural studies of animals exposed to bleomycin (52) and of humans poisoned with paraquat (53) suggest an increased number of fibroblasts within the alveolar interstitium.

Second, extensive study of both animal and human mononuclear phagocytes from a variety of anatomic sites demonstrates the ability of these cells to release growth factors augmenting fibroblast replication. Beginning with the work of Leibovich and Ross (54), studies with peritoneal macrophages derived from both mouse (55) and guinea pig (56), support the concept that mononuclear phagocytes release growth factor(s) for fibroblasts. Further support for this concept derives from the analysis of human mononuclear phagocytes in that both blood monocytes (57-61) and alveolar macrophages (7) are capable of releasing growth factors stimulating fibroblast replication.

Third, biochemical studies indicate that in human disease, the increase in collagen content observed in interstitial fibrosis is approximately proportional to the 
increase in fibroblast number, suggesting that on the average, collagen synthesis per cell remains constant. For example, lungs from patients with IPF have no increase in collagen content when normalized to the quantity of DNA (a parameter that is proportional to the number of cells) (62). In addition, lung slices from patients with fibrotic lung disorders have a normal rate of collagen synthesis per microgram of DNA (62).

In addition to releasing AMDGF, alveolar macrophages from patients with interstitial disease also release fibronectin (63), a mediator that may play a role in expanding fibroblast number in the alveolar walls in regions of ongoing inflammation. The importance of fibronectin in the pathogenesis of interstitial fibrosis is suggested by several observations: $(a)$ alveolar macrophages from patients with fibrotic lung disorders release up to 10 -fold more fibronectin than normals (63), (b) alveolar macrophage fibronectin is a potent chemoattractant for lung fibroblasts (63), (c) macrophage fibronectin not only is capable of attaching fibroblasts to type I collagen, but also attaches fibroblasts to Clq bound to immune complexes, permitting abnormal accumulations of fibroblasts in regions of inflammation and immune complex deposition (64), and $(d)$ attachment to a suitable substrate is required for fibroblast replication in response to growth factors such as AMDGF (65). Together, these observations suggest an important integrative function for the alveolar macrophage in the fibrotic process.

Regulation of fibroblast replication in the human alveolar wall. The dual control model of Pledger and co-workers (66), although it does not directly address the mechanism of action of growth workers, is a useful formalism for classifying the biological effects of growth factors. According to this concept, growth factors can be divided into competence factors and progression factors. Competence factors, such as FGF and PDGF, act early in $G_{1}$, permitting the target cell to respond later in $G_{1}$ to progression factors. Progression factors act sometime later in $G_{1}$ stimulating the target cell to synthesize DNA and divide. For optimal replication, both a competence and progression factor are required. Within this framework, AMDGF from normals and patients with interstitial lung disorders acts as a progression factor. Although nearly all previously described progression factors are insulinlike growth factors $(22,66)$ and interact with well characterized receptors (67), neither AMDGF from normals nor patients interact with these receptors. Interestingly, Clemmons et al. (68) have reported that under certain circumstances, fibroblasts can produce their own insulinlike growth factors. In this regard, preliminary evidence suggests that AMDGF acts by stimulating lung fibroblast production of insulinlike growth factors in a dose-dependent manner with the progression sig- nal mediated by fibroblast-derived insulinlike growth factors (69).

One prediction of the dual control model is that for fibroblast replication to occur within the alveolar structures, in addition to the progression signal provided by AMDGF, a competence signal must be present. In accord with this prediction, macrophage fibronectin, which is produced in increased amounts in fibrotic lung disorders, is known to act as a competence factor (8). Preliminary studies correlating clinical outcome of patients with interstitial lung disorders with the presence of alveolar macrophages releasing AMDGF and increased amounts of fibronectin suggest that, if both mediators are released, deterioration is very likely, and conversely, if both mediators are not released, deterioration is unlikely (70). These observations provide additional evidence in support of the alveolar macrophage as an an important integrator of the fibrotic process in interstitial lung disorders.

\section{ACKNOWLEDGMENTS}

The authors wish to thank $M$. Wewers for preparing the standards and performing the assays for interleukin-1, $P$. Pinkston for performing the interleukin-2 assays, S. P. Nissley for assistance in performing the assays for the insulinlike growth factors, and B. Keogh for performing the pulmonary function tests.

\section{REFERENCES}

1. Scadding, J. G. 1974. Diffuse pulmonary alveolar fibrosis. Thorax. 29:271-281.

2. Spencer, H. 1977. Pathology of the Lung. W. B. Saunders Co., Philadelphia.

3. Gaensler, E. A., M. V. B. Moister, and J. Hamm. 1964. Open-lung biopsy in diffuse pulmonary disease. N. Engl. J. Med. 270:1319-1331.

4. Spencer, H. 1967. Interstitial pneumonia. Annu. Rev. Med. 18:423-442.

5. Scadding, J. G., and K. F. W. Hinson. 1967. Diffuse fibrosing alveolitis (diffuse interstitial fibrosis of the lungs). Thorax. 22:291-304.

6. Brody, A. R., and J. E. Craighead. 1976. Interstitial associations of cells lining air spaces in human pulmonary fibrosis. Virchows Arch. Abt. A Pathol. Anat. 372:3949.

7. Bitterman, P. B., S. I. Rennard, G. W. Hunninghake, and R. G. Crystal. 1982. Human alveolar macrophage growth factor for fibroblasts. Regulation and partial characterization. J. Clin. Invest. 70:806-822.

8. Bitterman, P. B., S. I. Rennard, S. Adelberg, and R. G. Crystal. 1983. Role of fibronectin as a growth factor for fibroblasts. J. Cell Biol. In press.

9. Hunninghake, G. W., J. E. Gadek, T. J. Lawley, and R. G. Crystal. 1981. Mechanisms of neutrophil accumulation in the lungs of patients with idiopathic pulmonary fibrosis. J. Clin. Invest. 68:259-269.

10. Schoenberger, C. I., G. W. Hunninghake, Q. Kawanami, V. J. Ferrans, and R G. Crystal. 1982. Role of alveolar 
macrophages in asbestosis: modulation of neutrophil migration to the lung following acute asbestos exposure. Thorax. 37:803-809.

11. Venet, A., M. Wewers, and R. Crystal. 1982. Enhanced antigen presentation by alveolar macrophages of patients with sarcoidosis. Clin. Res. 30:360a. (Abstr.)

12. Fulmer, J. D., W. C. Roberts, E. R. von Gal, and R. G; Crystal. 1977. Small airways in idiopathic pulmonary fibrosis. Comparison of morphologic and physiologic observations. J. Clin. Invest. 60:595-610.

13. Siltzbach, L. E. 1980. Sarcoidosis. In Pulmonary Diseases and Disorders. A. P. Fishman, editor. McGraw Hill Book Co., New York. 889-908

14. Crystal, R. G., J. D. Fulmer, W. C. Roberts, M. L. Moss, B. R. Line, and H. Y. Reynolds. 1976. Idiopathic pulmonary fibrosis: clinical, histologic, radiographic, physiologic, scintigraphic, cytologic, and biochemical aspects. Ann. Intern. Med. 85:769-788.

15. Basset, F., B. Corrin, H. Spencer, J. Lacronique, C. Roth, P. Soler, J. P. Battesti, and J. Cretien. 1978. Pulmonary histiocytosis-X. Am. Rev. Respir. Dis. 118:811-820.

16. Hunninghake, G. W., and A. S. Fauci. 1979. State of the art: pulmonary disorders associated with the collagen vascular diseases. Am. Rev. Respir. Dis. 119:471-503.

17. Frieman, D. G., and H. C. Hardy. 1970. Beryllium disease. The relation of pulmonary pathology to clinical course and prognosis based on a study of 130 cases from the US Beryllium Case Registry. Human Pathol. 1:2544.

18. Roberts, R. C., and U. L. Moore. 1977. Immunopathogenesis of hypersensitivity pneumonitis. Am. Rev. Respir. Dis. 116:1075-1090.

19. Hunninghake, G. W., J. E. Gadek, Q. Kawanami, V. J. Ferrans, and R. G. Crystal. 1979. Inflammatory and immune processes in the human lung in health and disease: evaluation by bronchoalveolar lavage. Am. J. Pathol. 97:149-206.

20. Böyum, A. 1967. Isolation of mononuclear cells and granulocytes from human blood. Scan. J. Clin. Lab. Invest. 97(Suppl. 21):77-89.

21. Weiner, M., C. Bianco, and V. Nussenzweig. 1973. Enhanced binding of neuraminidase-treated sheep erythrocytes to human T-lymphocytes. Blood.42:939-946.

22. Stiles, C. D., G. T. Capone, C. D. Scher, H. N. Antoniades, J. J. Van Wyk, and W. J. Pledger. 1979. Dual control of cell growth by somatomedins and plateletderived growth factor. Proc. Natl. Acad. Sci. USA. 76:1279-1283.

23. Furlanetto, R. W., L. E. Underwood, J. J. Van Wyk, and A. J. D'Ercole. 1977. Estimation of somatomedin C levels in normals and patients with pituitary disease by radioimmunoassay. J. Clin. Invest. 60:648-657.

24. Moses, A. C., S. P. Nissley, P. A. Short, and M. M. Rechler. 1980. Immunological cross-reactivity of multiplication-stimulating activity polypeptides. Eur. J. Biochem. 103:401-408.

25. Rechler, M. M., J. M. Podskalny, and S. P. Nissley. 1977 Characterization of the binding of multiplication-stimulating activity to a receptor for growth polypeptides in chick embryo fibroblasts. J. Biol. Chem. 252:38983910.

26. Foley, T. P., Jr., S. P. Nissley, R. L. Stevens, G. L. King, V. C. Hascall, R. E. Humbel, P. A. Short and M. M. Rechler. 1982. Demonstration of receptors for insulin and insulin-like growth factors on swarm rat chondrosarcoma chondrocytes. Evidence that insulin stimulates proteoglycan synthesis through the insulin receptor. $J$. Biol. Chem. 257:663-669.

27. Mizel, B. S., J. J. Oppenheim, and D. L. Rosenstreich. 1978. Characterization of lymphocyte-activating factor (LAF) produced by the macrophage cell line, P388D I. Enhancement of LAF production by activated T-lymphocytes. J. Immunol. 120:1497-1503.

28. Gillis, S., M. M. Ferm, W. Ou, and K. A. Smith. 1978 T-cell growth factor: parameters of production and a quantitative microassay for activity. J. Immunol. 120:2027-2032.

29. Vogel, A., E. Raines, B. Kariya, M. J. Rivest, and R. Ross. 1978. Coordinate control of $3 \mathrm{~T} 3$ cell proliferation by platelet-derived growth factor and plasma components. Proc. Natl. Acad. Sci. USA. 75:2810-2814.

30. Mizel, S. B., J. J. Oppenheim, and D. L. Rosenstreich 1978. Characterization of lymphocyte-activating factor (LAF) produced by a macrophage cell line, P338D, II. Biochemical characterization of LAF induced by activated T-cells and LPS. J. Immunol. 120:1504-1508

31. Keogh, B. A., G. W. Hunninghake, B. R. Line, and R. G. Crystal. 1983. The alveolitis of pulmonary sarcoidosis: evaluation of natural history and alveolitis-dependent changes in lung function. Am. Rev. Respir. Dis. 128:256-265.

32. Keogh, B. A., J. Bernardo, G. W. Hunninghake, B. R Line, D. Price, and R. G. Crystal. 1983. Effect of intermittent high dose parenteral corticosteroids on the alveolitis of idiopathic pulmonary fibrosis. Am. Rev. Respir. Dis. 127:18-27

33. Keogh, B. A., and R. G. Crystal. Chronic interstitial lung disease. Current Pulmonol. 3:237-340

34. Line, B. R., J. D. Fulmer, H. Y. Reynolds, W. C. Roberts, A. E. Jones, E. K. Harris, and R. G. Crystal. 1978. Gallium-67 citrate scanning in the staging of idiopathic pulmonary fibrosis: correlation with physiologic and morphologic features and bronchoalveolar lavage. Am. Rev. Respir. Dis. 118:355-365.

35. Evans, M. J., and R. F. Bils. 1969. Identification of cells labelled with tritiated thymidine in the pulmonary alveolar walls of the mouse. Am. Rev. Respir. Dis. 100:372-378.

36. Hunninghake, G W., J. E. Gadek, R. C. Young, O. Kawanami, V. J. Ferrans, and R. G. Crystal. 1980. Maintenance of granuloma formation in pulmonary sarcoidosis by T-lymphocytes within the lung. N. Engl. J. Med. 303:594-598

37. Daniele, R. P., J. H. Dauber, and M. D. Rossman. 1980 Immunologic abnormalities in sarcoidosis. Ann. Intern Med. 92:406-416.

38. Crystal. R. G., G. W. Hunninghake, J. E. Gadek, B. A Keogh, S. I. Rennard, and P. B. Bitterman. 1982. The pathogenesis of sarcoidosis. In Proceedings of the IX International Conference on Sarcoidosis and Other Granulomatous Disorders. J. Chretien, J. Marsac, and J. C. Saltiel, editors. Pergamon Press, Paris. 13-35.

39. Bitterman, P. B., R. A. Robbins, J. E. Gadek, S. Adelberg, and R. G. Crystal. 1982. Alveolar macrophage-derived growth factor: a pathogenic link between alveolitis and interstitial fibrosis in interstitial lung disease. Am. Rev. Respir. Dis. 125(part 2):54a. (Abstr.)

40. Merrill, W. W., G. P. Naegel, R. A. Matthay, and H. Y. Reynolds. 1980. Alveolar macrophage-derived chemotactic factor. Kinetics of in vitro production and partial characterization. J. Clin. Invest 65:268-276.

41. Hunninghake, G. W., J. E. Gadek, H. M. Fales, and 
R. G. Crystal. 1980. Human alveolar macrophage-derived chemotactic factor for neutrophils. Stimuli and partial characterization. J. Clin. Invest. 66:473-483.

42. Crystal, R. G., J. E. Gadek, V. J. Ferrans, J. D. Fulmer, B. R. Line, and G. W. Hunninghake. 1981. Interstitial lung disease: current concepts of pathogenesis, staging, and therapy Am. J. Med. 70:542-568.

43. Siltzback, L. E. 1976. Seventh International Conference on Sarcoidosis and Other Granulomatous Disorders. Ann. NY Acad. Sci. 278.

44. Heppleston, A. G., and J. A. Styles, 1967. Activity of a macrophage factor in collagen formation by silica. $\mathrm{Na}$ ture (Lond.). 214:521-522.

45. Harrington, J. S., M. Ritchie, P. C. King, and K. Miller. 1973. The in vitro effects of silica-treated hamster macrophages on collagen production by hamster fibroblasts. J. Pathol. 109:21-37.

46. Nourse, L. D., P. N. Nourse, H. Botes, and H. M. Schwartz. 1975. The effects of macrophages isolated from the lungs of guinea pigs dusted with silica on collagen biosynthesis by guinea pig fibroblasts in cell culture. Environ. Res. 9:115-127.

47. Reiser, K. M., and J. A. Last. 1979. Silicosis and fibrogenesis: fact and artifact. Toxicology. 13:51-72

48. Crapo, J. D., M. Peters-Golden, J. Marsh-Salin, and J. S. Shelburne. 1978. Pathologic changes in the lungs of oxygen-adapted rats: a morphometric analysis. Lab. Invest. 39:640-653.

49. Pinkerton, K., P. Pratt, A. R. Brody, and J. D. Crapo. 1981. Lung injury patterns in rats as a result of exposure to different chrysotile asbestos fibers. Am. Rev. Respir. Dis. 123(part 2):149.

50. Thet, L. A., and J. D. Crapo. 1982. Morphometry of ultrastructural changes in the lung due to radiation injury. Am. Rev. Respir. Dis. 125(part 2):229.

51. Haschek, W. M., K. M. Reiser, A. J. P. Klein-Szanto, J. P. Kehrer, L. H. Smith, J. A. Last, and H. P. Witschi. 1983. Potentiation of butylated hydroxytoluene-induced acute lung damage by oxygen: cell kinetics and collagen metabolism. Am. Rev. Respir. Dis. 127:28-34.

52. Jones, A. W., and N. L. Reeve. 1978. Ultrastructural study of bleomycin-induced pulmonary changes in mice. J. Pathol. 124:227-233.

53. Dearden, L. C., R. D. Fairshter, D. M. McRae, W. R. Smithe, F. L. Giauser, and A. F. Wilson. 1978. Pulmonary ultrastructure of the late aspects of human paraquat poisoning. Am. J. Pathol. 93:667-676

54. Leibovich, S. J., and R. Ross. 1976. A macrophage-dependent factor that stimulates the proliferation of $\mathrm{fi}$ broblasts in vitro. Am. J. Pathol. 84:501-513

55. Martin, B. M., M. A. Gimbrone, Jr., E. R. Unanue, and R. S. Cotran. 1981. Stimulation of nonlymphoid mesenchymal cell proliferation by a macrophage-derived growth factor. J. Immunol. 126:1510-1515.

56. Wahl, S. M., L. M. Wahl, J. B. McCarthy, L. Chedid, and S. E. Mergenhagen. 1979. Macrophage activation by mycobacterial water soluble compounds and synthetic muramyl dipeptide. J. Immunol. 122:2226-2231.
57. DeLustro, F., G. K. Sherer, and E. C. LeRoy. 1980. Human monocyte stimulation of fibroblast growth by a soluble mediator(s). Res. J. Reticuloendothel. Soc. 28:519-532.

58. Glenn, K. C., and R. Ross. 1981. Human monocyte-derived growth factor(s) for mesenchymal cells: activation of secretion by endotoxin and concanavalin A. Cell. 25:603-615.

59. Rutherford, B., K. Steffin, and J. Sexton. 1982. Activated human mononuclear phagocytes release a substance(s) that induces replication of quiescent human fibroblasts. Res. J. Reticuloendothel. Soc. 31:281-293.

60. DeLustro, F., and E. C. LeRoy. 1982. Characterization of the release of human monocyte regulators of fibroblast proliferation. Res. J. Reticuloendothel. Soc. 31:295305.

61. Schmidt, J. A., S. B. Mizel, D. Cohen, and I. Green. 1982. Interleukin-1, a potential regulator of fibroblast proliferation. J. Immunol. 128:2177-2182.

62. Fulmer, J. D., R. S. Bienkowski, M. J. Cowan, S. D. Breul, K. M. Bradley, V. J. Ferrans, W. C. Roberts, and R. G. Crystal. 1980. Collagen concentration and rates of synthesis in idiopathic pulmonary fibrosis. Am. Rev. Respir. Dis. 122:289-301.

63. Rennard, S. I., G. W. Hunninghake, P. B. Bitterman, and R. G. Crystal. Production of fibronectin by the human alveolar macrophage: mechanism for the recruitment of fibroblasts to sites of tissue injury in interstitial lung diseases. Proc. Natl. Acad. Sci. USA. 78:7147-7151.

64. Rennard, S. I., Y. F. Chen, R. A. Robbins, J. E. Gadek, and R. G. Crystal. 1983. Fibronectin mediates cell attachment to Clq: a mechanism for the localization of fibrosis in inflammatory diseases. Clin. Exp. Immunol. In press

65. Hayflick, L., and P. S. Moorhead. 1961. The serial cultivation of human diploid cell strains. Exp. Cell Res. 25:585-621.

66. Pledger, W. J., H. N. Stiles, H. N. Antoniades, and C. D. Scher. 1978. An ordered sequence of events is required before $\mathrm{BALB} / \mathrm{C}-3 \mathrm{~T} 3$ cells became committed to DNA synthesis. Proc. Natl. Acad. Sci. USA 75:28392843

67. Kasuga, M., E. Van Oberghen, S. P. Nissley, and M. M. Rechler. 1981. Demonstration of two subty pes of insulinlike growth factor receptors by affinity cross-linking. $J$. Biol. Chem. 256:5305-5308.

68. Clemmons, D. R., L. E. Underwood, and J. J. Van Wyk. 1981. Hormonal control of immunoreactive somatomedin production by cultured human fibroblasts. $J$. Clin. Invest. 67:10-19.

69. Bitterman, P. B., S. I. Rennard, S. P. Nissley, S. Adelberg, and R. G. Crystal. 1982. Insulin-like growth factor production by fibroblasts: stimulation by alveolar macrophage-derived growth factor. Clin. Res. 30:385a. (Abstr.)

70. Bitterman, P. B., S. Rennard, B. Keogh, S. Adelberg, and R. G. Crystal. 1983. Chronic alveolar macrophage release of fibronectin and alveolar macrophage-derived growth factor correlates with functional deterioration in fibrotic lung disease. Clin. Res. 31:414a. (Abstr.) 